\title{
PREVENTION OF RUBBERY-SNOUT AND X-RAY REVEALATIONS ON HUNCHBACK CONDITION IN MUGGER CROCODILE (CROCODYLUS PALUSTRIS)
}

\author{
L.A.K. Singh ${ }^{1}$, S.S. Srivastava ${ }^{2}$, A.P. Mohanty and S.D. Rout \\ ${ }^{1}$ Research Officer, ${ }^{2}$ Field Director, \\ Similipal Tiger Reserve, Baripada, Orissa 757002, India. \\ Email:simitig@dte.vsnl.net.in, sheo@operamail.com,laksingh33@hotmail.com
}

\begin{abstract}
Mugger crocodiles in captivity are prone to osteological problems such as hunchback and rubbery-snout. Detection of hunchback is possible only in advanced stages and is observed generally in young muggers. Externally, the vertex of the hunch appears at the level of the fifth or sixth row of dorsal scutes. X-ray photographs of affected muggers in Ramtirtha revealed points of deossification at three sites around the eighth, twentieth and twenty-seventh vertebrae. Yearlings suffering from rubbery-snout showed normalcy in seven days when fed with Calcium tablets. Calcium-rich feed is recommended in crocodile husbandry to avoid osteological defects.
\end{abstract}

\section{Keywords \\ Crocodylus palustris, hunchback, rubbery-snout, calcium therapy, Ramatirtha}

\section{Introduction}

Conditions of hunchback, horizontal neck-bent, vertical neckbent and tail-bents are reported as congenital and also defects arising later in life in gharial, Gavialis gangeticus (Singh, 1978; Singh \& Bustard, 1982). When congenital, these defects are related to desiccation of eggs.

Mugger crocodiles (Crocodylus palustris) reared in captivity are prone to one common osteological defect, the hunchback, perhaps preceded with an indicator condition of rubbery-snout. At the mugger rearing facility in Ramatirtha, under Similipal Tiger Reserve, rubbery-snout conditions were curable, but the detection of hunchback was possible only at an advanced stage. Hunchback muggers have trouble in swimming and often drown to death. Observations related to x-ray of hunchback and experience with preventing rubbery-snout are presented below for possible feedback from other crocodile

Received on 6 October 2000

Accepted on 28 January 2001 rearing facilities.

\section{Occurrence of hunchback}

The occurrence of hunches, were normally first noticed in yearlings or hatchlings six months old. In hatchlings it was not very clear and in yearlings the detection was at an advanced stage of the condition. A juvenile mugger was suspected to have the defect when it was seen 'gyrating' on the surface of water or showing pursuits of abnormal swimming.

When viewed externally, the vertex of the hunch appeared at the level of the fifth or sixth row of dorsal scutes counted from the front to back (anterior hunch) or back to front (posterior hunch) (Fig. 1). In early stages the ascent of the hunch was gradual but it tapered when the defect persisted and grew. Only either of the two hunches -- the anterior or posterior -- developed for any particular individual, although, as revealed later from x-ray photographs, anatomically weak points may have existed at other points too.

\section{$\mathrm{X}$-ray interpretation}

When x-ray photographs of one hunchback were viewed from different angles, points of deossification were noticed at three potential sites -- around the eighth, twentieth and twenty-seventh vertebrae (Fig. 2). The point where the hunch was prominent the vertebral column appeared detached and the affected vertebrae were either very thin or replaced by soft tissue (Fig. 3).

\section{Possible link to rubbery-snout}

In several cases at Ramatirtha, rubbery-snouts, without signs of hunch, were detected during routine health checks of hatchlings and small yearlings kept in hatchling-pens. It was a condition in which the snout, jaws and the head could be bent from the sides when pressed between two fingers. The head felt like a flexible toy crocodile. Such yearling muggers were forcefed with Calcium tablets (Sandoz) 500mg/day. Within seven days of administration of the tablets, the snout reaffirmed and felt normal. On such occasions the muggers were continued with calcium-therapy for 15-30 days. Calcium-therapy has been a normal practice at Ramatirtha whenever rubbery-snout is detected. 


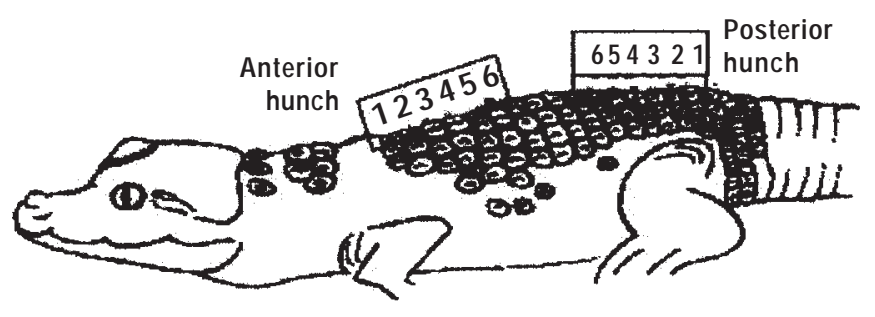

Figure 1. A normal hatchling of Crocodylus palustris showing anterior and posterior hunch
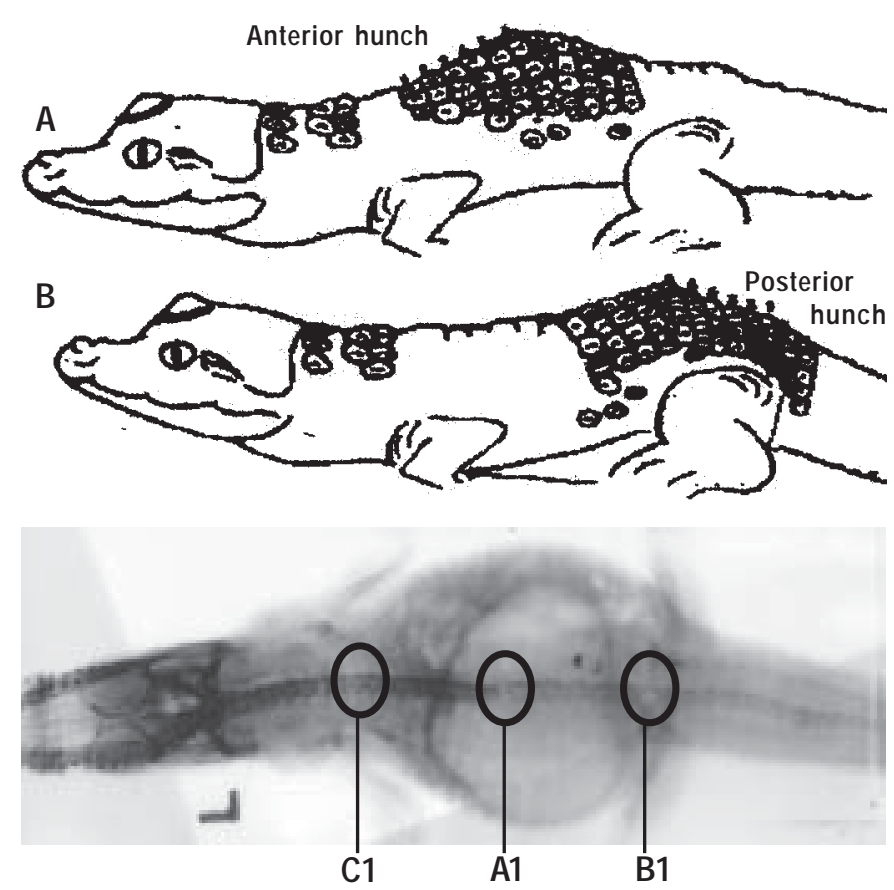

Figure 2. External appearance and x-ray photograph showing points of deossification at eighth, twentieth and twentyseventh vertebrae of Crocodylus palustris. A1 - Anterior hunch; B1 - Posterior hunch; C1 - Bent neck.

\section{Discussion}

Hunchback condition appears related to deossification and may precede with the condition of rubbery-snout. While hunchback is difficult to detect unless it becomes advanced, rubbery-snout is difficult to detect with older juveniles as they are housed in large pools. Therefore, prevention of appearance of the condition is the choice.

In crocodile husbandry, it is usually recommended that when the food consists chiefly of boneless meat, a diet of fish, crab, prawn, molluscs, undressed birds, large insects and soft mammalian bones offered weekly or fortnightly may prevent the
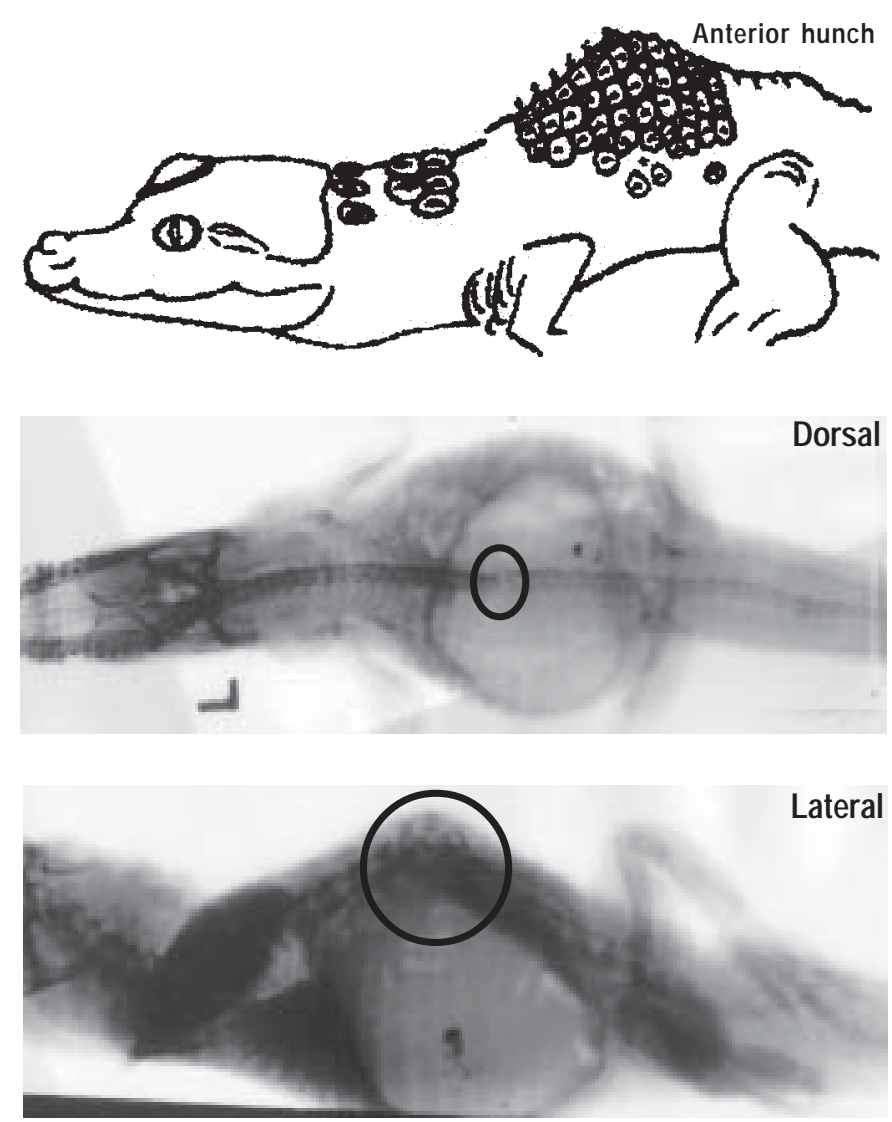

Figure 3. Anterior hunch showing detached vertebral column.

appearance of rubbery-snouts, which is an osteological problem arising due to calcium deficiency.

Even otherwise, if rubbery-snout is detected early, an immediate change to calcium-therapy may reset the snout to normal and prevent the appearance of hunches. In the light of the above, all hatchling muggers should be checked at least once a week and older juveniles as often as possible for rubbery-snout condition.

\section{Acknowledgements}

We are grateful to the government of Orissa and Principal Chief Conservator of Forests (Wildlife)-cum-Chief Wildlife Warden, Orissa for encouragement and facilities to work with muggers. We also acknowledge the assistance received from staff at the Mugger Crocodile Research and Conservation Unit, Ramatirtha.

\section{Reference}

Singh, L.A.K. (1978). Ecological studies on Indian Gharial Gavialis gangeticus (Gmelin) (Reptilia, Crocodilia) with special reference to growth rate. Ph.D. thesis. Utkal University, Bhubaneswar.

Singh, L.A.K. and H.R. Bustard (1982). Congenital defects in the gharial Gavialis gangeticus (Gmelin). British Journal of Herpetology 6(7): 215-219. 